\title{
Costello Sendromunda Kardiyak Tutulum: Altı Olgunun Değerlendirilmesi
}

\author{
Cardiac Involvement in Costello Syndrome: Evaluation of Six Cases
}

\begin{abstract}
Fahrettin Uysal, Özlem Mehtap Bostan, Evren Semizel*, Filiz Akaltun**, Gülcan Üner**, Ergün Çil

Uludağ Üniversitesi Tıp Fakültesi, Çocuk Kardiyoloji Anabilim Dalı, Bursa, Türkiye

*Sağlik Bakanlı̆̆ı Dörtçelik Çocuk Hastalıkları Hastanesi, Çocuk Kardiyoloji, Bursa, Türkiye

**Uludağ Üniversitesi Tıp Fakültesi, Çocuk Sağlığı Anabilim Dalı, Bursa, Türkiye
\end{abstract}

Yazısma Adresi/Address for Correspondence Dr. Fahrettin Uysal, Uludağ Üniversitesi Tip Fakültesi, Çocuk Kardiyoloji Anabilim Dall, Bursa, Türkiye Tel.: + 902242950454 E-posta: fahrettin_uysal@mynet.com

Geliş Tarihi/Received: 28.01.2013 Kabul Tarihi/Accepted: 20.06.2013

(c) Güncel Pediatri Dergisi, Galenos Yayinevi tarafindan basılmış̧tr.

(c) The Journal of Current Pediatrics, published by Galenos Publishing.

\section{ÖZET}

Giriş: Costello sendromu postnatal büyüme ve gelişme geriliği, kaba yüz, gevşek deri, ilerleyici olmayan kardiyomiyopati ve sempatik kişilik ile karakterize otozomal dominant geçiş gösterdiği düşünülen bir sendromdur. Bu çalışmanın amacı Costello sendromu tanısı konulan ve konjenital kalp hastalığı olan altı olgunun klinik bulgularının değerlendirilmesidir.

Gereç ve Yöntem: Çalışmada üfürüm nedeni ile çocuk kardiyoloji polikliniğine 2002-2013 yılları arasında başvuran ve Costello sendromunun fenotipik özellikleri olan 6 olgu değerlendirildi. Olguların yakınmaları, klinik bulguları, tedavi ve klinik gidişi incelendi.

Bulgular: Olguların 3'ü kız, 3'ü erkekti ve ortalama yaşları $34 \pm 12$ ay (7 ay-11 yaş) idi. Tüm hastalarda kaba yüz görünümü, el içi ve ayak tabanı çizgilerinde belirginlik, hipertelorizm, epikantus, basık burun kökü ve kardiyak muayenelerinde üfürüm mevcut idi. Hastaların hepsinde konjenital kalp hastalığı saptandı. Hastaların 5 'inde değișik derecelerde pulmoner stenoz saptandı ve bu hastaların 3'üne balon pulmoner valvüloplasti yapıldı. 3 hastada atriyal septal defekt tespit edilirken 1 hastada hipertrofik kardiyomiyopati saptandı. 2 hastada mental retardasyon mevcut idi.

Sonuç: Psikomotor gelişme geriliği, kaba yüz görünümü, seyrek saçları, derin avuç içi ve ayak tabanı çizgileri olan ve depo hastalığı düşünülen hastalarda özellikle pulmoner stenoz veya hipertrofik kardiyomiyopati varlığında Costello sendromu mutlaka akla gelmelidir.(Güncel Pediatri 2013; 11: 63-7)

Anahtar kelimeler: Costello sendromu, kardiyomiyopati, pulmoner kapak stenozu, kaba yüz, depo hastalığı

\section{SUMMARY}

Introduction: Costello syndrome is probably an autosomal dominant inherited disorder that is characterized by postnatal growth retardation, developmental delay, coarse facies, loose skin, nonprogressive cardiomyopathy and friendly behavior. The aim of this study was to evaluate a variety of clinical findings and cardiac involvement of six patients diagnosed as Costello syndrome.

Materials and Methods: Six cases that had a typical features of Costello syndrome admitted to pediatric cardiology department due to cardiac murmur between 2002-2013 years were evaluated. Their complaints, clinical findings, treatments and clinical courses were examined.

Results: Three of the patients were male and the mean age of patients was $34 \pm 12$ months (7 months to 11 years). All of the cases had coarse faces, deep palmar and plantar creases, hypertelorism, epicanthal folds, depressed nasal bridges and cardiac murmur at auscultation. Congenital heart disease was found in all patients. Five patients had pulmonary stenosis and balloon pulmonary valvuloplasty was performed in 3 of these patients. Atrial septal defect was detected in 3 patients and 1 of the patient had hypertrophic cardiomyopathy. Mental retardation was found in 2 patients.

Conclusions: Costello syndrome must be keep in mind in all patients with psychomotor retardation, coarse faces, sparse hairs, deep palmar and plantar creases, phenotypical features resembling a storage disease especially in association with pulmonary stenosis and hypertrophic cardiomyopathy. (Journal of Current Pediatrics 2013; 11: 63-7)

Key words: Costello syndrome, cardiomyopathy, pulmonary valve stenosis, coarse facies, storage disease 


\section{Giriş}

Costello sendromu ilk defa 1971 ve 1977 yllında Costello tarafından, psikomotor gelişme geriliği, büyüme geriliği, makrosefali ve kaba yüz görünümü, kısa boynu, seyrek kıvırcık saçları, gevşek el sırtı derisi ve nazal papillomları olan 2 çocukta tanımlanmıştır $(1,2)$. Literatürde 100'den fazla olgu bildirilmiştir $(3,4)$.

Çoğunlukla bu hastalar kaba yüz görünümleri ve gelișme geriliği nedeni ile mukopolisakkaridozlar veya depo hastalıkları açısından araștııımaktadırlar. Özellikle derin palmar ve plantar çizgileri, el bileğinin ulnar deviasyonu, tipik saçları ve gevşek derisi olan hastalarda kardiyolojik değerlendirmede pulmoner kapak stenozu veya hipertrofik kardiyomiyopati saptanırsa tanı kesindir.

Costello sendromu tanısı almış 94 hastanın kardiyolojik açıdan değerlendirildiği bir çalışmada hastaların \%63'ünde kardiyak sorun olduğu tespit edilmiştir (5). En sık görülen anormallikler pulmoner kapak stenozu, hipertrofik kardiyomiyopati, septal defektler ve ritim sorunları olarak belirtilmiştir.

Bu çalışmada üfürüm nedeni ile çocuk kardiyoloji polikliniğimize başvuran ve fenotipik özellikleri ile Costello Sendromu tanısı konan 6 olgu kardiyak tutulum açısından değerlendirilerek sunulmuştur.

\section{Bulgular}

Olguların 3'ü kız, 3'ü erkek olup yaşları 7 ay-11 yaş (34 \pm 12 ay) idi. Üç olguya iki aylık iken tanı konulurken en geç tanı konulan olgu dört yaşında idi. Hastaların hepsi kardiyak muayenelerinde üfürüm duyulması nedeni ile gönderilmişlerdi. Iki hastada prenatal dönemde polihidramnios öyküsü mevcuttu. Üç olgunun doğum ağırlığı normal iken üç olgunun doğum ağırlığı > 4000 gr idi.

Yapılan fizik muayenede 3 hastanın ağırlık ve boy ölçümleri üçüncü persentilin altında iken kaba yüz görünümü hepsinde vardı (Resim 1 ve Resim 2). Illk üç olguda saçlar seyrek ve kıvırcık yapıdayken, bir olguda kalın kaşlar ve artmış kıllanma görüldü (Resim 3). El içi ve ayak tabanı çizgilerindeki belirginlik tüm hastalarda ortak bulgu idi (Resim 4A ve Resim 4B). Aynı şekilde hipertelorizm, epikantus ve basık burun kökü tüm olgularda saptandı. Iki hastada makroglossi görüldü (Resim5). Bir yaşın üzerinde olan 2 olgunun mental gelişiminin geri olduğu görüldü.

Son 2 olgu kaba yüz görünümünden dolayı çocuk metabolizma polikliniğinde depo hastalıkları yönünden tetkik edilmişti ve tüm hastaların metabolik tetkikleri normal saptanmıştı. Hastaların klinik özellikleri Tablo 1'de gösterilmiştir.

Tüm olgularda konjenital kalp hastalığı saptandı. Birinci olgu ağır mitral kapak prolapsusu ve ağır mitral yetmezliği nedeni ile 11 yaşına kadar medikal tedavi ile izlendi ve bu hastaya protez mitral kapak replasmanı yapıldı.

Diğer olguların hepsinde değişik derecelerde pulmoner kapak stenozu saptandı. Displastik pulmoner kapağı ve orta dereceli pulmoner kapak stenozu olan üç hastaya
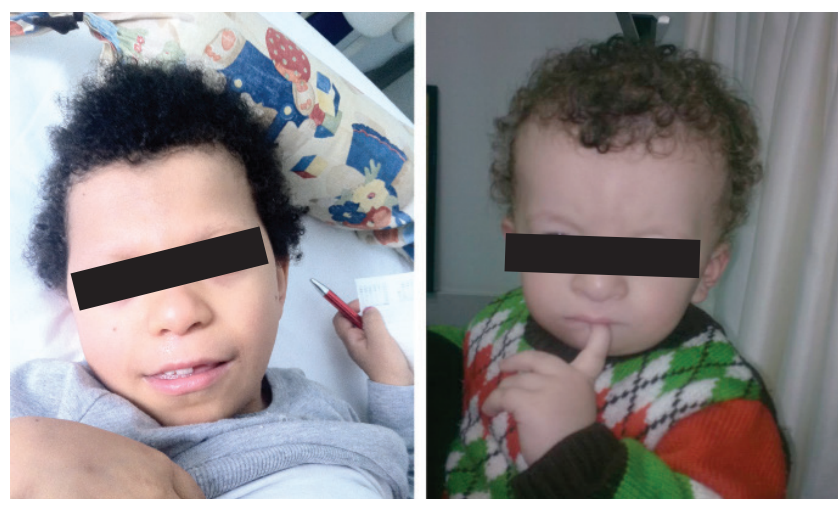

Resim 1, 2. Olgu 1 ve 2'nin kaba yüz görünümleri ve kıvırcık, seyrek saçları

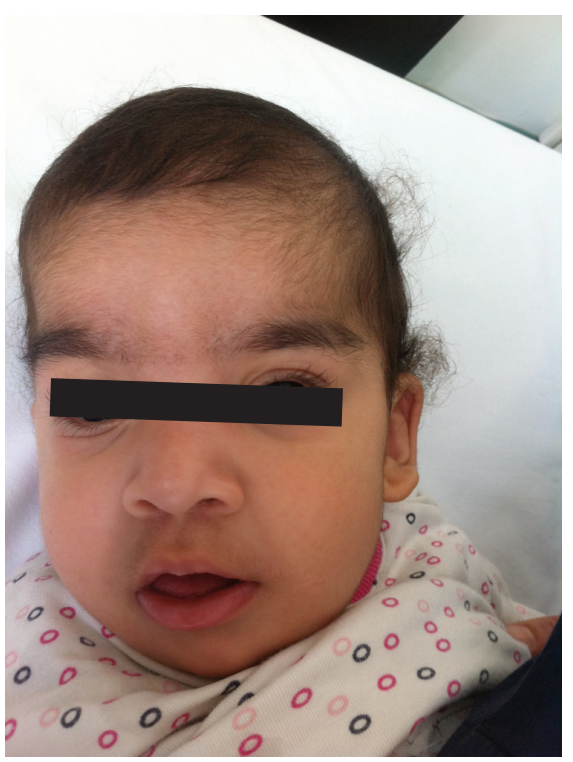

Resim 3. Kalın kaşları ve alında artmış kıllanma olan bir olgu

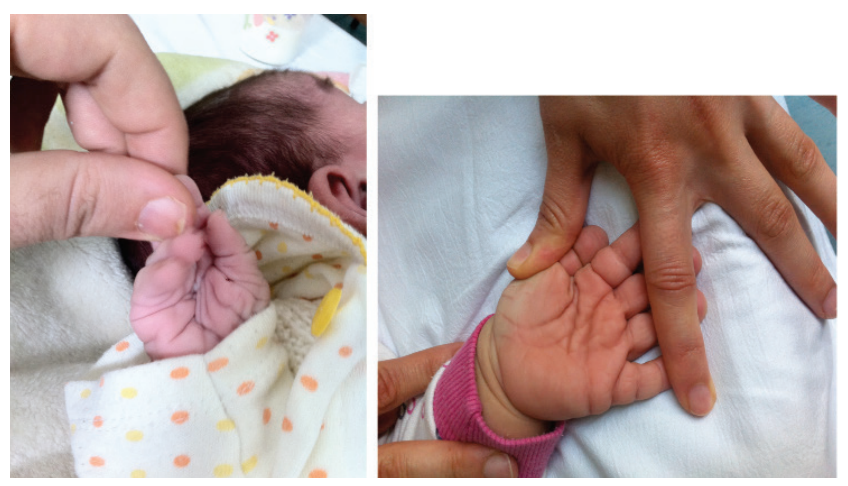

Resim 4. Íki olgudaki avuç içi çizgilerdeki belirginlik 


\begin{tabular}{|c|c|c|c|c|c|c|c|}
\hline \multicolumn{2}{|c|}{ Klinik özellikler } & Olgu 1 & Olgu 2 & Olgu 3 & Olgu 4 & Olgu 5 & Olgu 6 \\
\hline \multicolumn{2}{|c|}{ Polihidramnios } & + & - & - & + & - & - \\
\hline \multicolumn{2}{|l|}{ Iri doğum } & + & - & + & + & - & - \\
\hline \multicolumn{2}{|l|}{ Kaba yüz } & + & + & + & + & + & + \\
\hline \multicolumn{2}{|l|}{ Makroglossi } & - & - & - & - & + & + \\
\hline \multicolumn{2}{|c|}{ Kalın kaşlar ve kıllanma artışı } & - & - & + & - & - & - \\
\hline \multicolumn{2}{|c|}{ Dolgun yanaklar } & + & + & + & - & + & + \\
\hline \multicolumn{2}{|c|}{ Seyrek ve gevşek saçlar } & + & + & + & - & - & - \\
\hline \multicolumn{2}{|c|}{ Derin palmar çizgiler } & + & + & + & + & + & + \\
\hline \multicolumn{2}{|c|}{ Diş anomalileri } & + & - & - & - & - & - \\
\hline \multicolumn{2}{|l|}{ Gevşek deri } & + & + & - & + & - & + \\
\hline \multicolumn{2}{|c|}{ Inguinal papillom } & + & - & - & - & - & - \\
\hline \multicolumn{2}{|l|}{ Epikantus } & + & + & + & + & + & + \\
\hline \multicolumn{2}{|c|}{ Büyüme geriliği } & + & + & - & - & - & + \\
\hline \multicolumn{2}{|c|}{ Psikomotor geliş̧me geriliği } & + & + & - & - & - & - \\
\hline \multirow{5}{*}{ 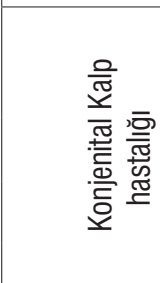 } & Pulmoner stenoz & - & + & + & + & + & + \\
\hline & ASD & - & - & - & + & + & + \\
\hline & Mitral kapak anomalisi & + & - & - & + & - & - \\
\hline & Septal hipertrofi & - & - & - & + & - & - \\
\hline & Disritmi & + & - & - & - & - & - \\
\hline
\end{tabular}

pulmoner balon valvüloplasti uygulanırken bir hastaya pulmoner valvotomi yapıldı.

Üç hastada atriyal septal defekt saptanırken bir hastada asimetrik septal hipertrofisi tespit edildi.

Tüm hastalara 24 saatlik ritim holter uygulaması yapıldı ve sadece bir olguda supraventriküler taşikardi mevcuttu ve medikal tedavi ile düzeldi.

\section{Tartışma}

Son yillarda Costello sendromunun fenotipik özelliklerinin daha iyi tanımlanması ile birlikte bu hastalığın sıkığında belirgin bir artış olmuştur. Çoğu hastada gebelikte polihidramnios olduğu bildirilmiştir (3). Sunulan olguların ikisinde gebelikte polihidramnios öyküsü mevcuttu.

Costello sendromunda iri doğum ve doğumdan sonra büyüme geriliğinin olması sık görülen bir bulgudur (8). Bu sendromda yüz görünümü tipiktir ve kaba yüz, düşük kulaklar, kıvırcık seyrek saçlar, kıllanmış alın, epikantal kıvrımlar, dolgun yanaklar, makroglossi, basık burun kökü, kalın kaşlar, büyük kulaklar, strabismus ile karakterizedir
$(3,4)$. Kaba yüz görünümlerinden dolayı bu hastalar depo hastalıkları yönünden araștııımaktadırlar. Çalışmamızda tüm hastaların kaba yüz görünümü vardı ve 2 vaka da bu özelliğinden dolayı metabolizma polikliniğinden depo hastalıkları yönünden araştııımış ve tüm metabolik incelemeleri normal bulunmuştu.

Costello sendromunda gevşek deri, palmar ve plantar çizgilerdeki belirginlik çok sık rastlanılan bir bulgudur (9). Hastaların parmakları uzun süre suda kalmış gibi görünür. Bizim de tüm hastalarda deri değişiklikleri saptanmıştı. Çeşitli vaka sunumlarında bu hastaların çoğunda saçların seyrek ve kıvırcık olduğu bildirilmiştir (10-13). Yapılan bir araştırmada literatürde bildirilen hastaların \%82'sinde saçlar seyrek ve kıvırcık idi (3). Çalışmamızda üç vakanın saçları tipik görünümde iken diğer üç vakada saç değişikliği yoktu. Papillomaların ise görülme yaşı ortalama 6 (2-15) yaş olarak bildirilmiştir ve neredeyse vakaların yarısında saptanmamıştır $(11,14)$. Bizim sadece bir olgumuzda inguinal bölgede papillom görülmüştür.

Costello sendromlu hastalarda bașta embriyonel rabdomiyosarkom olmak üzere çeşitli tümörlere karşı 
belirgin risk artışı mevcuttur (15). Gripp ve arkadaşları bu hastalarda doğumdan 10 yaşına kadar 6 ayda bir abdominopelvik ultrasonografi ile taranmasını, 5 yaşına kadar yılda bir idrar katekolamin düzeylerinin bakılmasını ve 10 yaşından itibaren de yıllık hematüri izleminin yapılmasını önermiştir (7).

Costello sendromunda prognozu belirleyen en önemli iki faktör kardiyak sorunlar ve psikomotor gelişme geriliğidir. Bugüne kadar bildirilen vakaların hemen hepsinde çeşitli derecelerde mental ve motor gerilik mevcuttur (16). Eeghen ve ark.'nın yapmış olduğu çalışmada hastaların IQ'larının 47-85 arasında değiştiği bildirilmiştir (4). Çalışmamızda 2 olguda belirgin gelişme geriliği mevcut idi. Diğer hastalar ise bu yönden takip edilmektedirler.

Lin ve arkadaşlarının yaptığı çalışmada hastaların \%63'ünde kardiyak sorun olduğu görülmüştür (5). Çeşitli sunumlarda en sık görülen kardiyak sorunlar pulmoner stenoz, hipertrofik kardiyomiyopati, atriyal septal defekt, ventriküler septal defekt ve nadiren mitral kapak stenozu, biküspit aorta olarak bildirilmiştir $(4,17,18)$. Yazımızda sunulan olguların hepsi tarafımıza muayenelerinde üfürüm olması nedeni ile yönlendirilmişti ve Costello sendromu tanısı konmamıştı. Hastaların hepsinde konjenital kalp hastalığı tespit edildi ve fenotipik özellikleri ile beraber Costello sendromu tanısı kondu. Beş hastada çeşitli derecelerde pulmoner kapak stenozu saptandı ve bu hastaların 3'üne katater anjiyografi ve balon pulmoner valvüloplasti uyguland. Bir hastada balon pulmoner valvüloplasti sonrası ağır pulmoner stenozun tekrarlaması üzerine pulmoner valvotomi uygulandı. Bir olguda ise ağır mitral stenozu ve yetersizliği olması nedeni ile 11 yaşında mitral kapak replasmanı yapııdı. Hastaların 3'ünde atriyal septal defekt tespit edildi. Literatürde septal hipertrofi, hastaların \%50'sine yakınında görülebilmekte ve ilerleyici olabilmekte olup (5), sadece bir hastada çok ciddi obstruktif hipertrofik kardiyomiyopatiye bağlı ölüm bildirilmiştir (19). Bizim ise sadece bir hastamızda asimetrik septal hipertrofi saptandı ve izlemde hastanın septal hipertrofisi düzeldi. Tüm hastalarımız hipertrofik kardiyomiyopati açısından izlenmektedir.

Bu hastalarda aritmi ilk kez 1993'te Izumikawa ve arkadaşları tarafından tanımlanmış olup hastaların çoğunda atriyal taşikardi şeklinde olduğu gösterilmiştir $(13,20,21)$. Bu hastalarda görülen aritminin kardiyomiyopati olmadan da gelişebileceği gösterilmiştir. Tüm hastalara 24 saatlik ritm holter yapıldı ve sadece bir vakada supraventriküler taşikardi gelişti ve medikal tedavi ile kontrol altına alındı.

Costello sendromu, kendisinin de içinde olduğu Rasopati sendromları arasında yer alan Kardiyo-Fasio-
Kutanöz sendromu, Noonan sendromu, LEOPARD sendromu, Legius sendromu, Nörofibromatosus Tip-1 gibi sendromlarla karışabilir. Tüm bu sendromlarda pulmoner stenoz ve ASD görülebilirken Costello sendromunda en önemli farklar özellikle saç ve deri değişiklikleridir. HRAS genindeki mutasyonlara bakılarak genetik tanı mümkündür ancak çalışmamızda vakalara karakteristik klinik özellikleri ile tanı kondu $(6,22,23)$.

Sonuç olarak Costello sendromu çok geniş bir klinik yelpaze ile karşımıza çıkabilir. Özellikle psikomotor gelişme geriliği, kaba yüz görünümü, seyrek saçları, derin avuç içi ve ayak tabanı çizgileri olan hastalarda özellikle pulmoner stenoz veya hipertrofik kardiyomiyopati varlığında Costello sendromu mutlaka akla gelmelidir ve hastalar bu sendromun diğer özellikleri yönünden araştııımalıdırlar.

\section{Kaynaklar}

1. Costello JM. A new syndrome. NZ Med J 1971;74:397.

2. Costello JM. A new syndrome: mental subnormality and nasal papillomata. Aust Paediatr J 1977;13:114-8.

3. Hennekam RC. Costello syndrome: an overview. Am J Med Genet C Semin Med Genet 2003;117:42-8.

4. van Eeghen AM, van Gelderen I, Hennekam RC. Costello syndrome: report and review. Am J Med Genet 1999;82:18793.

5. Lin AE, Grossfeld PD, Hamilton RM, Smoot L, Gripp KW, Proud $\mathrm{V}$, et al. Further delineation of cardiac abnormalities in Costello syndrome. Am J Med Genet 2002;111:115-29.

6. Gripp KW, Lin AE, Stabley DL, Nicholson L, Scott Cl Jr, Doyle D, et al. HRAS mutation analysis in Costello syndrome: genotype and phenotype correlation. Am J Med Genet A 2006;140:1-7.

7. Gripp KW. Tumor predisposition in Costello syndrome. Am J Med Genet C Semin Med Genet 2005;137:72-7.

8. Gripp KW, Scott CI Jr, Nicholson L, Figueroa TE. Second case of bladder carcinoma in a patient with Costello syndrome. Am J Med Genet 2000;90:256-9.

9. Martin RA, Jones KM. Delineation of the Costello syndrome. Am J Med Genet1991;41:346-9.

10. DerKaloustian VM, Moroz B, McIntosh N, Watters AK, Blaichman S . Costello syndrome. Am J Med Genet1991;41:69-73.

11. Teebi AS, Shaabani IS. Further delineation of Costello syndrome. Am J Med Genet 1993;47:166-8.

12. Mori M, Yamagata T, Mori Y, Nokubi M, Saito K, Fukushima $Y$, et al. Elastic fiber degeneration in Costello syndrome. Am J Med Genet 1996;61:304-9.

13. Zampino G, Mastroiacovo P, Ricci R, Zollino M, Segni G, Martini-Neri ME, et al. Costello syndrome: further clinical delineation, natural history, genetic definition, and nosology. Am J Med Genet 1993;47:176-83.

14. Czeizel AE, Tímár M. Hungarian case with Costello syndrome and translocation t(1,22). Am J Med Genet 1995;57:501-3.

15. Gripp KW, Scott Cl Jr, Nicholson L, McDonald-McGinn DM, Ozeran JD, Jones MC, et al. Five additional Costello syndrome patients with rhabdomyosarcoma: proposal for a tumor screening protocol. Am J Med Genet 2002;108:80-7. 
16. Kawame H, Matsui M, Kurosawa K, Matsuo M, Masuno M, Ohashi $\mathrm{H}$, et al. Further delineation of the behavioral and neurologic features in Costello syndrome. Am J Med Genet 2003;118:8-14.

17. Johnson JP, Golabi M, Norton ME, Rosenblatt RM, Feldman GM, Yang SP, et al. Costello syndrome: phenotype, natural history, differential diagnosis, and possible cause. J Pediatr 1998;133;441-8.

18. Siwik ES, Zahka KG, Wiesner GL, Limwongse C. Cardiac disease in Costello syndrome. Pediatrics 1998;101:706-9.

19. Tomita H, Fuse S, Ikeda K, Matsuda K, Chiba S. An infant with Costello syndrome complicated with fatal hypertrophic obstructive cardiomyopathy. Acta Paediatr Jpn 1998;40:608-11.
20. Izumikawa Y, Naritomi K, Tohma T, Shiroma N, Hirayama K. The Costello syndrome: a boy with thick mitral valves and arrhythmias. Jpn J Hum Genet 1993;38:329-34.

21. Say B, Güçsavaş M, Morgan H, York C. The Costello syndrome. Am J Med Genet 1993;47:163-5.

22. Aoki Y, Niihori T, Kawame H, Kurosawa K, Ohashi H. Germline mutations in HRAS proto-oncogene cause Costello syndrome. Nat Genet 2005;37:1038-40.

23. Utine GE. RA Sopatiler: Nöro-Kardiyo-Fasiyo-Kutanöz Sendromlar. Turkiye Klinikleri J Pediatr 2011;7:92-8. 